\title{
A EXPLORAÇÃO DO CAMARÃO ESCAVADOR CALLICHIRUS MAJOR SAY 1818 COMO ISCA EM UMA PRAIA URBANA (PERNAMBUCO, BRASIL)
}

\author{
Lago, C.E.M. ${ }^{1}$; Moura, M.K.M. ${ }^{1}$; Costa, L.B. ${ }^{1}$; Carvalho, P.V.V.C. ${ }^{1}$ \& Botter-Carvalho, M.L. ${ }^{1,}$ \\ ${ }^{1}$ Universidade Federal Rural de Pernambuco (UFRPE), Departamento de Biologia, Campus Recife, \\ Laboratório de Ecologia do bentos Costeiro (Lebenc).
}

*Autor correspondente: monicabotter@yahoo.com.br

\begin{abstract}
No litoral brasileiro a exploração do camarão escavador Callichirus major (Decapoda: Callianassidae), conhecido popularmente como "corrupto", foi documentada inicialmente na região Sudeste em meados da década de 1980 e difundiu-se nos anos subsequentes pelos litorais Sul e Nordeste. Todavia, até o presente há poucas informações sobre os aspectos, demográficos, sociais e econômicos relacionados à exploração do C. major como recurso natural. Visando contribuir para o preenchimento de tais lacunas, o presente trabalho teve por objetivo caracterizar a atividade de coleta de C. major como isca em uma praia urbana do Nordeste do Brasil. O estudo foi desenvolvido em um trecho de $5 \mathrm{~km}$ de extensão na praia de Piedade (Pernambuco) onde a exploração da espécie é registrada desde o final da década de 1990. Foram realizadas 11 campanhas de entrevistas, entre setembro de 2017 e junho de 2018, empregando um esforço amostral de 4h/dia, dividido em 2h antes e após o pico da baixa-mar. Foram aplicados questionários semiestruturados, abordando aspectos demográficos, sociais, econômicos (valoração do recurso natural), preferências qualitativas na coleta de iscas e à percepção dos respondentes sobre o impacto negativo desta atividade sobre a espécie-alvo. Foram identificadas três categorias de respondentes: pescadores não coletores (apenas utilizam iscas para pescar peixes); pescadorescoletores (coletam e utilizam iscas) e coletores de iscas. A bomba de sucção foi único instrumento de coleta. Dos 68 entrevistados, $100 \%$ eram do sexo masculino, dos quais $68 \%$ adultos, e $67 \%$ residiam na localidade. Do total, $42 \%$ eram pescadores não coletores; $49 \%$ pescadores-coletores e $9 \%$ coletores de iscas. Cerca de $47 \%$ possuíam atividade econômica formal, 39\% estavam desempregados e 14\% aposentados. Quanto ao uso de C. major como recurso natural, 92,3\% declararam utilizá-lo como isca; 4,6\% para alimentação e $3,1 \%$ para comercialização. A preferência por animais grandes foi declarada por 36,5\% dos entrevistados. As iscas não utilizadas imediatamente são conservadas em salmoura e congeladas para uso posterior. C. major é comercializado em garrafas plásticas reutilizadas, contendo de 25-30 animais, pelo valor de $\mathrm{R} \$ 10,00$. Sobre os impactos causados a espécie, 40,7\% dos entrevistados acreditam que a coleta não a afeta negativamente, mas são favoráveis à restrições legais visando prevenir os possíveis impactos da exploração.
\end{abstract}

Palavras-chave: Crustacea, Axiidea, isca, pesca. 